\title{
Polychloroprene behaviour in a marine environment: Role of silica fillers
}

\author{
Tchalla Siwavi Tatiana ${ }^{1,2}$, Le Gac Pierre-Yves ${ }^{1,{ }^{*}}$, Maurin R. ${ }^{3}$, Créac'Hcadec R. ${ }^{2}$
}

1 Ifremer, Service Matériaux et Structures, Centre de Brest BP70, 29280 Plouzané, France

2 ENSTA Bretagne, FRE CNRS 3744, Institut de Recherche Dupuy de Lôme, F-29200 Brest, France

${ }^{3}$ EDF - R\&D, Material\&Mechanics of Components Division - T28 Group, EDF Lab les Renardières, Avenue des Renardières, 77818 Moret Sur Loing, France

* Corresponding author : Pierre-Yves Le Gac, email address : mailto:pierre.yves.le.gac@ifremer.fr

\begin{abstract}
:
Polychloroprene rubbers are widely used in marine structures and often filled with silica in order to increase mechanical properties. The presence of silica fillers leads to a complex degradation of the material. This study aims to understand the deeper degradation mechanisms involved when a silica filled polychloroprene is used in sea water. To do so, 4 polychloroprene rubbers filled with different amounts of silica (from 0 to $45 \mathrm{phr}$ ) were aged in natural sea water for 6 months at temperatures ranging from 25 to $60{ }^{\circ} \mathrm{C}$. Moreover, a natural rubber with similar formulation was also considered in order to evaluate the role of the chlorine atom in the degradation. . The chemistry and mechanics of the rubber degradation were also studied. In the presence of water and silica fillers, a large decrease in rubber stiffness was observed. This was attributed to the breakage of hydrogen bonds involved in the interaction between the silica and chloroprene matrix and the process is reversible. In the meantime, silica undergoes hydrolysis that leads to silanol formation and so an increase in rubber stiffness when water is removed; this process is irreversible.
\end{abstract}

Keywords : Polychloroprene, Seawater, Silica filler, Hydrolysis 
Introduction

Polymers are widely used in marine structures in order to reduce weight, to prevent corrosion or improve thermal insulation, or as adhesives [1-3]. When polymers are used in such harsh environments for a long period (more than 20 years), the question of durability and ageing is raised. The immersion of polymer in sea water leads to a diffusion of water from the external medium into the polymer, the amount and rate of water absorption depends on the nature of the polymer and water temperature. The presence of water within the polymer leads to physical degradation, such as plasticisation where water increases mobility between macromolecular chains and so decreases mechanical properties. This kind of degradation is fully reversible, i.e. when water is removed the mechanical properties revert back to their initial state [4]. The presence of water can also lead to irreversible degradation such as additive leaching or hydrolysis that would also affect mechanical properties of the materials; in this case when the water is removed mechanical properties are still affected [5-6].

In the specific case of polychloroprene rubbers, they are mainly used as a coating in order to protect structures from corrosion or as sealing material [7-9]. Whereas this method is widely used for coating, the durability of such rubber in a severe environment is not fully understood. This can be explained by the fact that the long term behaviour of rubbers depends largely on its formulation [10, $11,12]$. In fact, it has been shown that water absorption in such rubbers is directly related to additives used for the vulcanization process [6,13]. Moreover, it appears from previous studies that the use of silica in polychloroprene rubber is useful to increase mechanical properties but is also involved in a complex degradation mechanism when used in sea water $[14,15]$ that will be considered in this study.

It has been observed many times that silica fillers can be used as reinforcing filler in rubbers in the same way as carbon black. In fact, the presence of inorganic fillers leads to an increase in rubber stiffness and stress at break due to the replacement of a soft matrix by hard inorganic filler [16]. Silica fillers are used, instead of carbon black, because this provides a unique combination of tear strength, abrasion resistance and adhesion properties [17]. In the specific case of silica fillers in polychloroprene rubber, it has been shown that reinforcing is not only due to the presence of hard filler in the soft matrix but also due to a strong interaction between the filler and the rubber. In fact, according to Sae-oui and al. [18] (Figure 1), a hydrogen bond exists between the silanol group present at the silica surface and the chlorine atom that can be represented as follows:

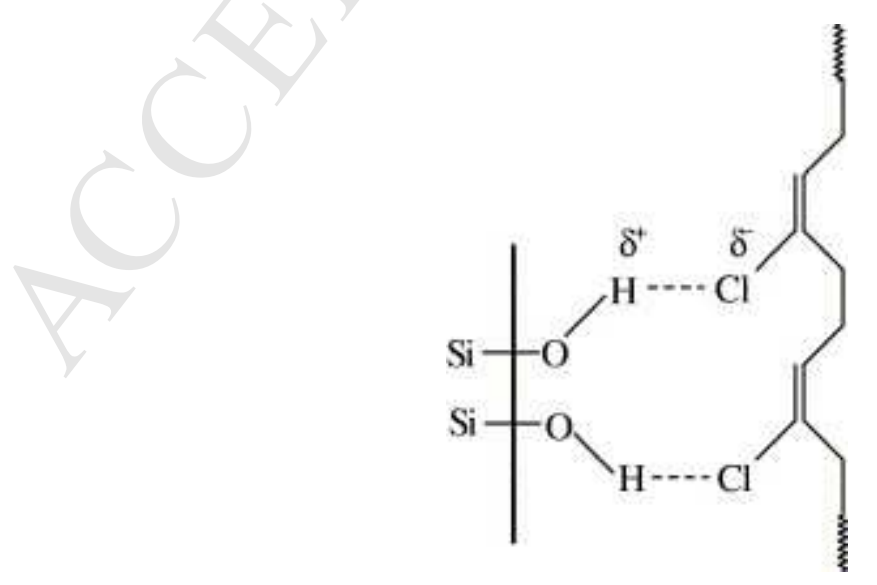

Figure 1: Interaction between the CR and silica filler [18].

Whereas silica filler allows an increase in the initial properties, it also appears that the presence of such a filler in the CR leads to a specific degradation when used in sea water that has 
been partially studied in the past. We have shown that silica undergoes hydrolysis that leads to the formation of a silanol group and an increase in stiffness in both accelerated and natural ageing [14]. However, in some cases, it has been shown that the CR stiffness is largely decreased when such material is used in sea water [19]. There is a clear lack of knowledge on the degradation mechanism involved in the degradation of silica filled CR when used in a marine environment and thus on the effect of ageing on the mechanical properties.

This study aims to highlight the exact role of silica fillers in the degradation of polychloroprene rubber used in a marine environment. To do so, 5 different rubbers were aged in sea water for 6 months at temperatures ranging from 25 to $60^{\circ} \mathrm{C}$ and then characterized in terms of chemistry and mechanical properties. The 5 rubbers that will be presented in the next section were chosen not only in order to study the role of the amount of filler in the CR $(0,15,30$ and $45 \mathrm{phr})$ but also the role of the nature of the matrix using a natural rubber with the same amount of filler. Experimental results will be presented with the mechanical properties directly after ageing (wet conditions) and after drying in order to distinguish reversible and irreversible processes involved in the complex degradation. Finally, a discussion of the results obtained will be presented in order to conclude on the exact role of silica fillers on the durability of CR in a marine environment. 
Materials and Methods

Materials

In this study, 5 different rubbers were considered, 4 polychloroprene samples with different amounts of silica filler $(0,15,30$ and $45 \mathrm{phr})$ and one natural rubber filled with $45 \mathrm{phr}$ of silica. Details on the material formulation are in Table 1. It is worth noting that no coupling agent is used with the silane group in this formulation.

A common commercial silica Ultrasil VN3 $[20,21]$ is used here. The polychloroprene used is a WN-1 grade and the Natural rubber is of SMR CV-50 type.

\begin{tabular}{|l|l|l|l|l|l|}
\hline \# of rubber & 1 & 2 & 3 & 4 & 5 \\
\hline Nature of the matrix & CR & CR & CR & CR & NR \\
\hline Amount of silica filler (phr) & 0 & 15 & 30 & 45 & 45 \\
\hline Density & 1.29 & 1.33 & 1.39 & 1.38 & 1.12 \\
\hline
\end{tabular}

(a)

\begin{tabular}{|l|l|}
\hline Other CR fillers & Amount (phr) \\
\hline ZnO & 5 \\
\hline $\mathrm{MgO}$ & 4 \\
\hline Stearic acid & 0.5 \\
\hline ETU & 1 \\
\hline TMQ & 2 \\
\hline
\end{tabular}

\begin{tabular}{|c|c|}
\hline Other NR fillers & Amount (phr) \\
\hline $\mathrm{ZnO}$ & 5 \\
\hline Sulfur & 1.5 \\
\hline Stearic acid & 2 \\
\hline CNS & 1.5 \\
\hline TMQ & 2 \\
\hline
\end{tabular}

(b)

(c)

Table 1: Detailed formulation of rubbers used in this study: (a) Matrix and Silica Filler. (b) and (c): Other fillers

Methods

Ageing

Specimens were immersed in several tanks filled with natural sea water coming directly from the Brest estuary (Brittany, France) and maintained at different temperatures: $25,40,60^{\circ} \mathrm{C}$. The temperature accuracy was $+/-1^{\circ} \mathrm{C}$. Water was continually renewed using a peristaltic pump leading to the replacement of the vessel volume every $24 \mathrm{~h}$ without any modification of the temperature. $2 \mathrm{~mm}$ thick plates were removed periodically from the tanks. To remove water, some samples were dried in a France Etuves XFO5O oven (Chelles, France) at $30^{\circ} \mathrm{C}$ in a vacuum in order to prevent oxidation during drying; the drying process was continued until a constant weight was reached.

Mass variation 
The water diffusion was determined from the weight evolution of square samples ( $30 \mathrm{~mm} \times 30 \mathrm{~mm}$ ) which were $2 \mathrm{~mm}$ thick. Mass gain was followed by periodic weighing on a Sartorius LA $310 \mathrm{~S}$ balance (precision $0.1 \mathrm{mg}$ ). Samples were removed from the ageing containers and wiped with paper towels to dry the surfaces before weighing. The mass change $(\mathrm{M}(\mathrm{t})$ ) of each sample at time $t$ is expressed in (Eq1) as a percentage such that:

$$
M(t)=\frac{m(t)-m_{0}}{m_{0}} .100 \quad(\text { Eq } 1)
$$

Where $m(t)$ is sample mass at time $t$ and $m o$ is the initial sample mass before immersion. For each condition (temperature, pressure and thickness), 3 samples were weighed to ensure the reliability of the measurement.

Tensile Test

Tensile tests were performed using standard dog bone specimens (type H3 from ISO 37 [22]) on an Instron machine with a displacement rate of $10 \mathrm{~mm} / \mathrm{min}$. Longitudinal sample deformation was measured using digital image correlation and load was measured using a $500 \mathrm{~N}$ load cell. For each condition, three samples of $2 \mathrm{~mm}$ thickness were tested. The experimental modulus $\mathrm{E}_{\mathrm{ex}}$ considered here is the ratio $\sigma / \varepsilon$ at an infinitesimally small strain tensile modulus (strain $\varepsilon \leq 10 \%$ ).

$$
E_{e x}=\frac{d \sigma}{d \varepsilon}
$$

Fourier Transform Infrared Spectroscopy (FTIR)

Chemical modifications during ageing were followed by FTIR spectroscopy in reflection mode at the sample surface. During exposure, FTIR analyses were performed on a Perkin Elmer Spectrum 2 with a resolution of $4 \mathrm{~cm}^{-1}$ and 32 scans for each test. The specific band situated at $825 \mathrm{~cm}^{-1}$ can be used as a reference to normalise the spectra in order to compare results [23].

Scanning Electron Microscopy with Energy-Dispersive Spectroscopy analysis (SEM/EDS)

The dispersion of fillers was characterized with SEM-EDS analysis using a FEI Quanta 200 scanning electron microscope and the energy dispersive X-ray spectroscopy compositional data were obtained using Oxford Instruments Microanalysis System with Xmax 80 detector. The fracture surfaces of unaged and aged samples were observed after being sputter-coated with a thin gold layer.

\section{Results}

This section is dedicated to the presentation of the main results obtained in this study with the aim of understanding the role of silica fillers in the degradation of polychloroprene rubbers.

\section{Mass Change}

First, the water absorption in the rubber is considered. Water absorption in polymers is usually measured based on mass variations [2-6]. Here, the mass variation of the $30 \mathrm{phr}$ silica filled polychloroprene is plotted as a function of time for $25,40,60^{\circ} \mathrm{C}$ (Figure 2a). Water uptake is usually plotted as a function of the square root of the time normalised by sample size (Figure $2 b$ ) in order to highlight Fickian or non-Fickian behaviour. When water absorption follows a Fickian behaviour, the curve is linear as long as the water absorption is less than half of the maximal water uptake and then achieves a plateau. Here, for CR filled with 30phr of silica we can observe a decrease after the maximum; this decrease could be related to an irreversible degradation of the polymer [24] and will 
be discussed later. This behaviour is observed for all temperatures considered here, i.e. 25, 40 and $60^{\circ} \mathrm{C}$. Moreover, Figure 3 shows that the presence of silica in the rubber increases the water absorption rate when samples are immersed in sea water at $40^{\circ} \mathrm{C}$ and it appears that the higher the silica content the larger the mass decrease.

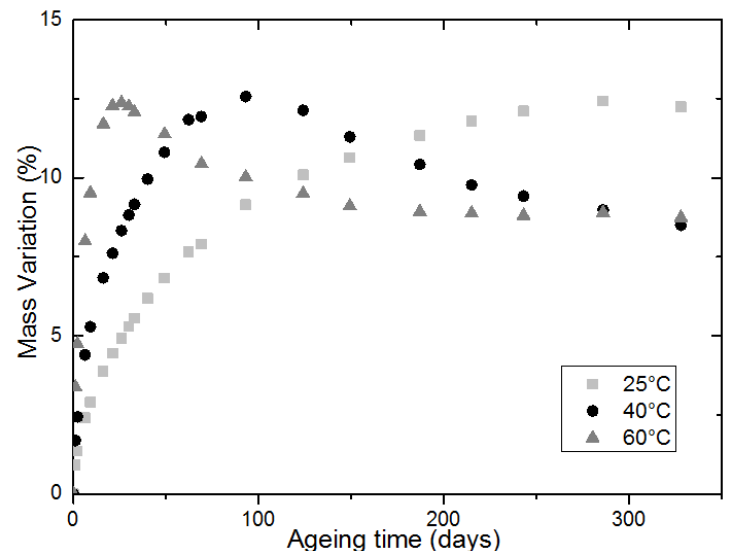

(a)

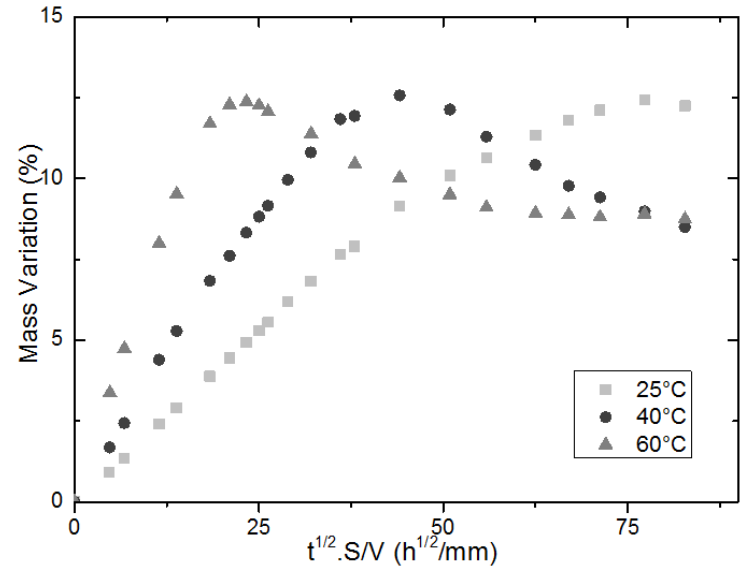

(b)

Figure 2: Mass variation for 30phr silica filled CR immersed in natural sea water at several temperatures: (a) as a function of time and (b) as a function of normalised square root of time.

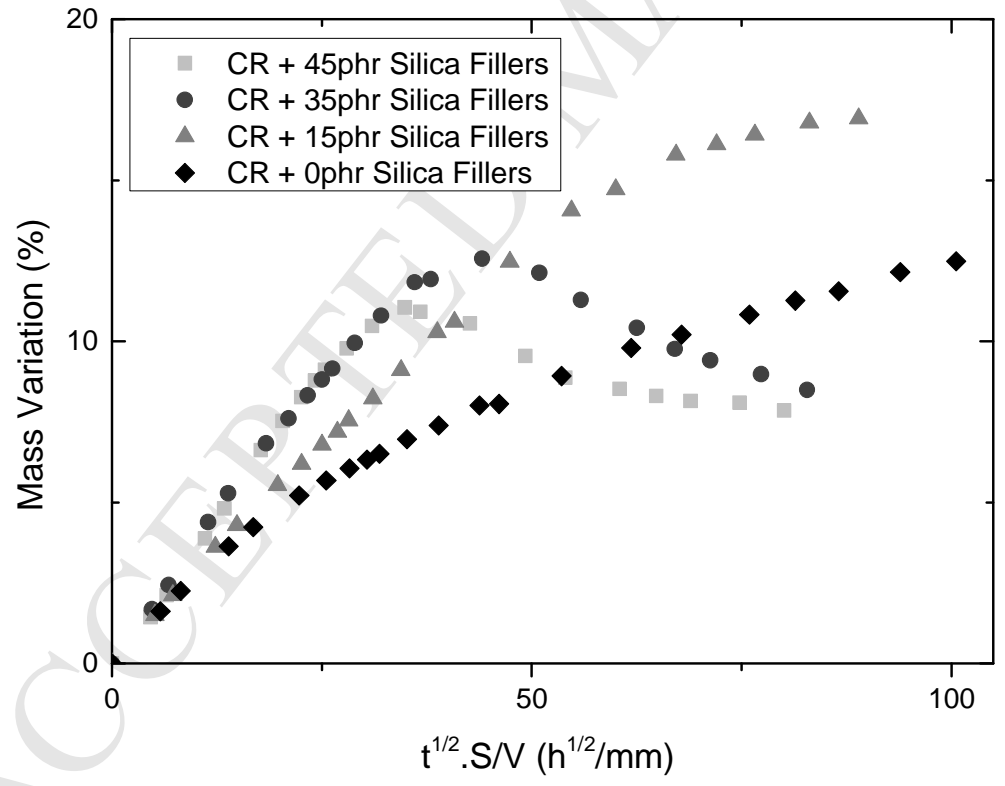

Figure 3: Effect of silica content in CR on mass variation when samples are immersed in sea water at $40^{\circ} \mathrm{C}$

Although water absorption is relevant information when considering the durability of polymers in a marine environment, we are usually more interested in changes in mechanical behaviour; this is the goal of the next section. 
Tensile results in wet conditions

This part is dedicated to the presentation of tensile behaviour of the CR immersed in sea water at different temperatures in order to investigate the role of water when silica is used as a reinforcing filler. Figures 4 to 6 where the nominal stress is plotted as a function of the nominal strain show the results obtained with CR filled with $30 \mathrm{phr}$ of silica. For all ageing temperatures, a rapid decrease in the rubber stiffness is observed when immersed in sea water and this is especially true for the low deformation (under $200 \%$ ). At $60^{\circ} \mathrm{C}$, for an ageing duration of 6 months, an increase in this stiffness is observed and will be considered in detail later. We can also observe that the elongation at break is not clearly affected by the degradation induced by immersion in sea water.

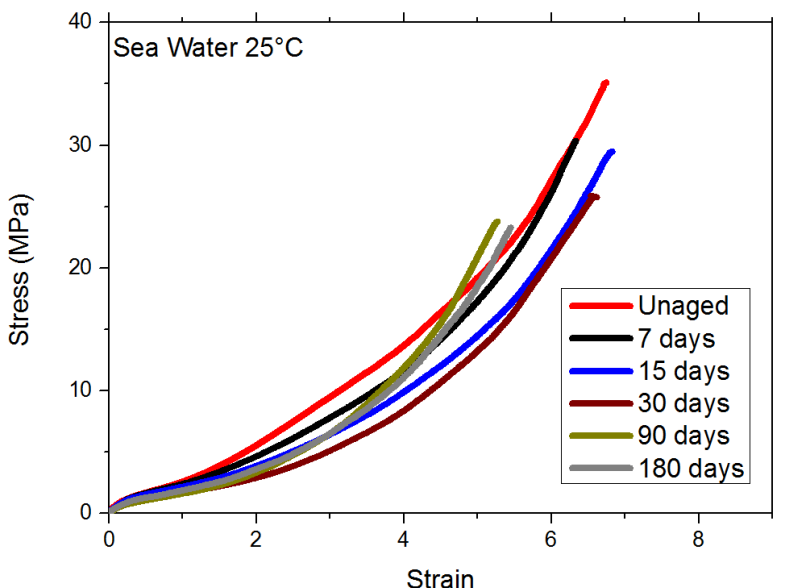

(a)

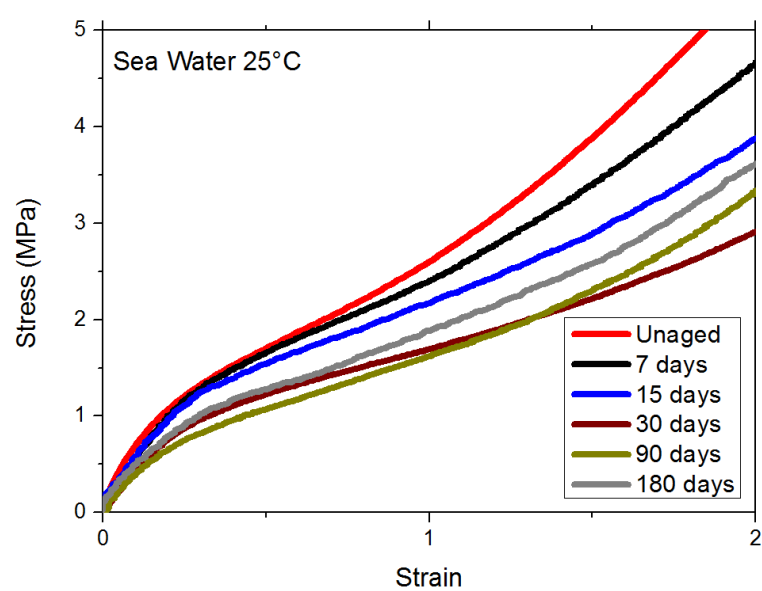

(b)

Figure 4: Tensile curves of CR with 30phr of silica as a function of immersion time in sea water at $25^{\circ} \mathrm{C}$ : (a) Stress-strain curves and (b) Zoom on the results for low strain

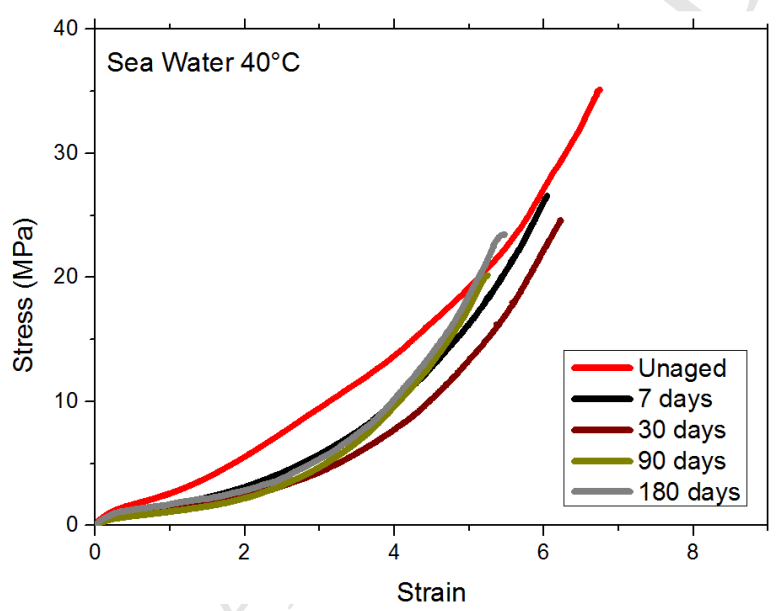

(a)

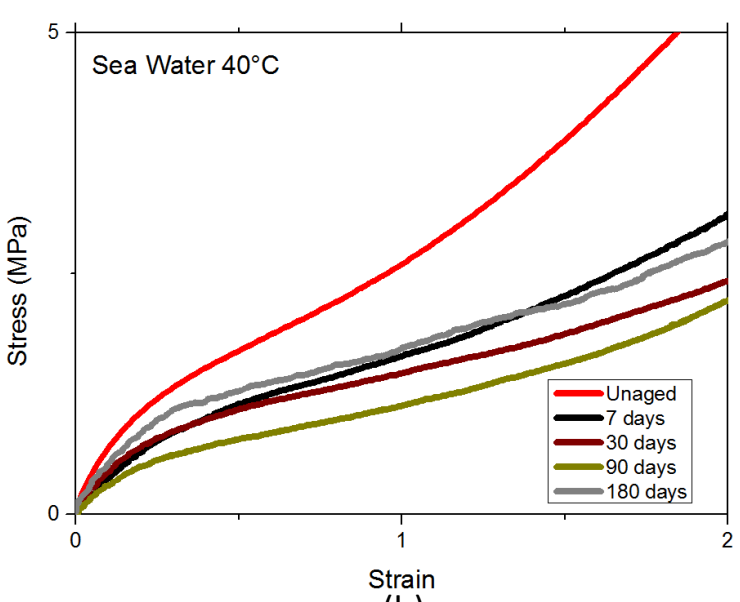

(b)

Figure 5: Tensile curves of CR with 30phr of silica as a function of immersion time in sea water at $40^{\circ} \mathrm{C}$ : (a) Stress-strain curves and (b) Zoom on the results for low strain 


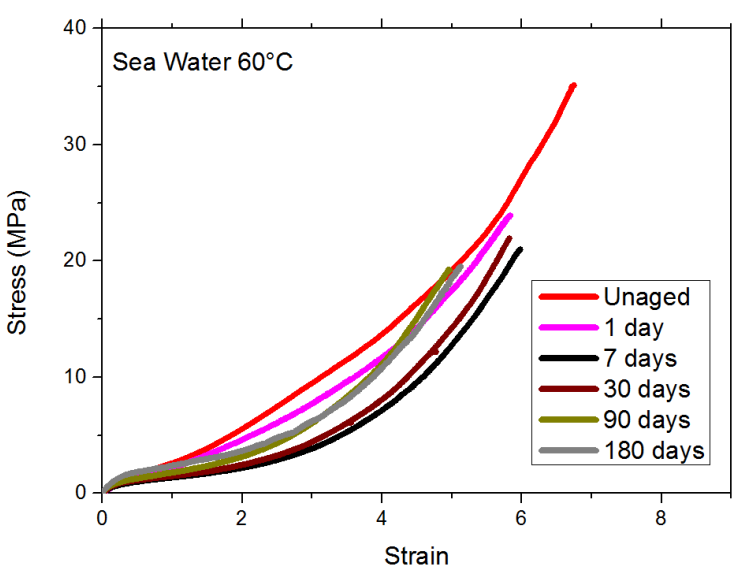

(a)

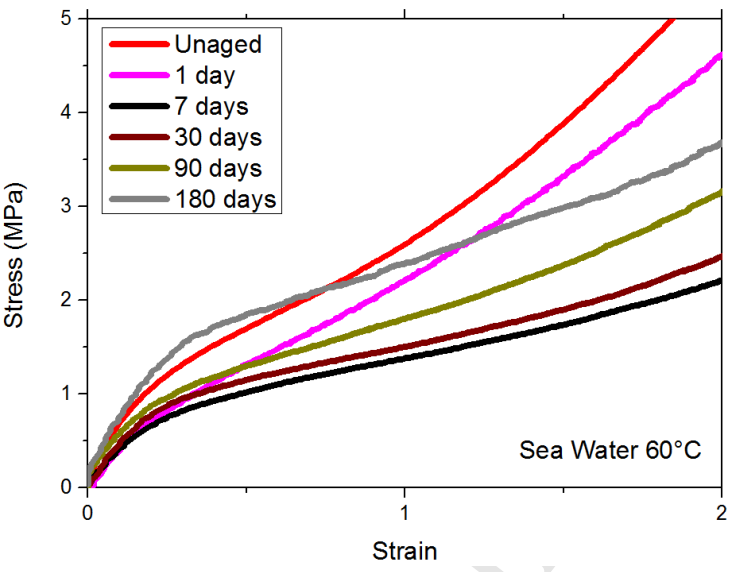

(b)

Figure 6: Tensile curves of $\mathrm{CR}$ with $30 \mathrm{phr}$ of silica as a function of immersion time in sea water at $60^{\circ} \mathrm{C}$ :

(a) Stress-strain curves and (b) Zoom on the results for low strain

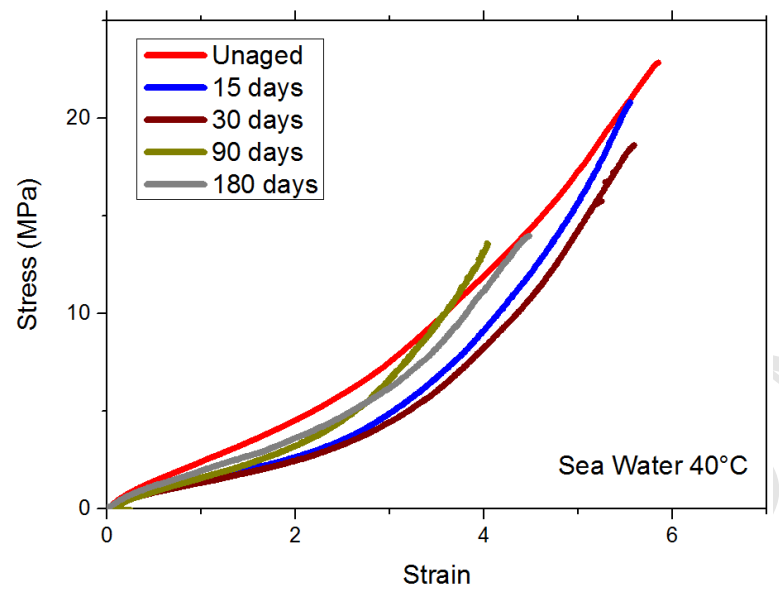

(a)

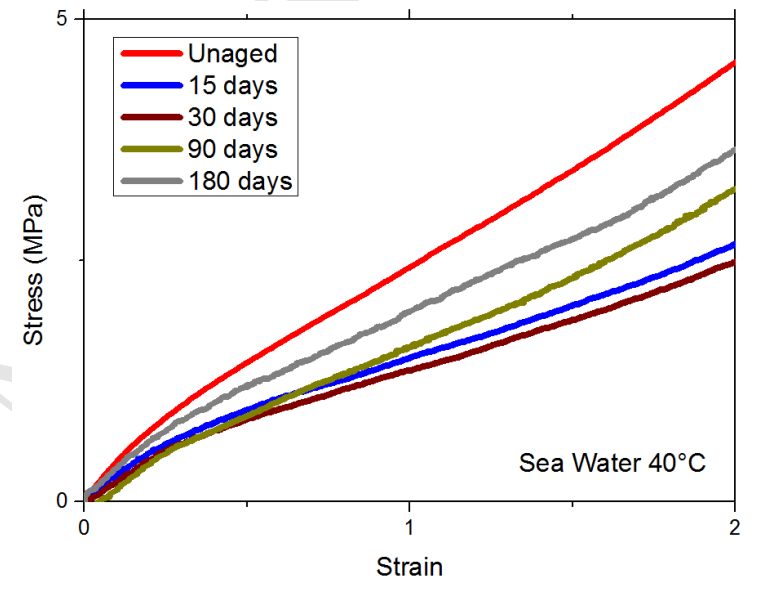

(b)

Figure 7: Tensile curves of CR with $15 \mathrm{phr}$ of silica as a function of immersion time in sea water at $40^{\circ} \mathrm{C}$ : (a) Stress-strain curves and (b) Zoom on the results for low strain

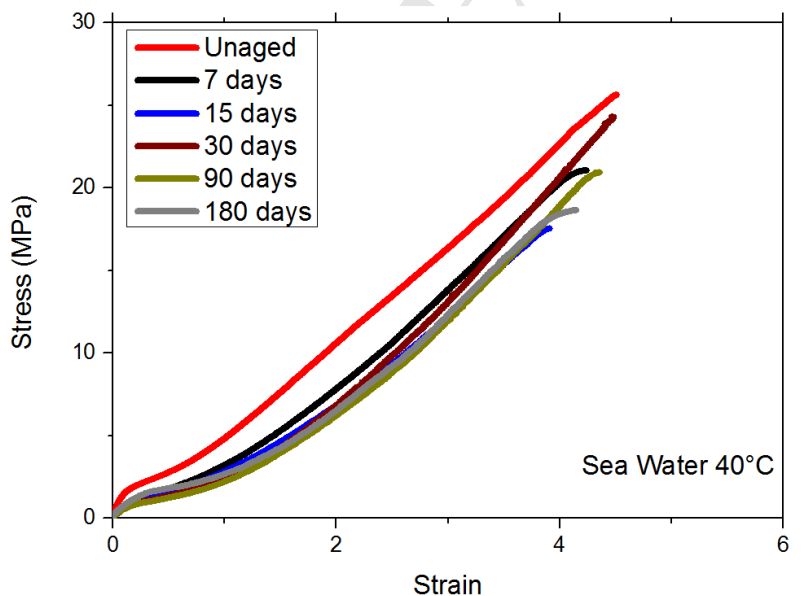

(a)

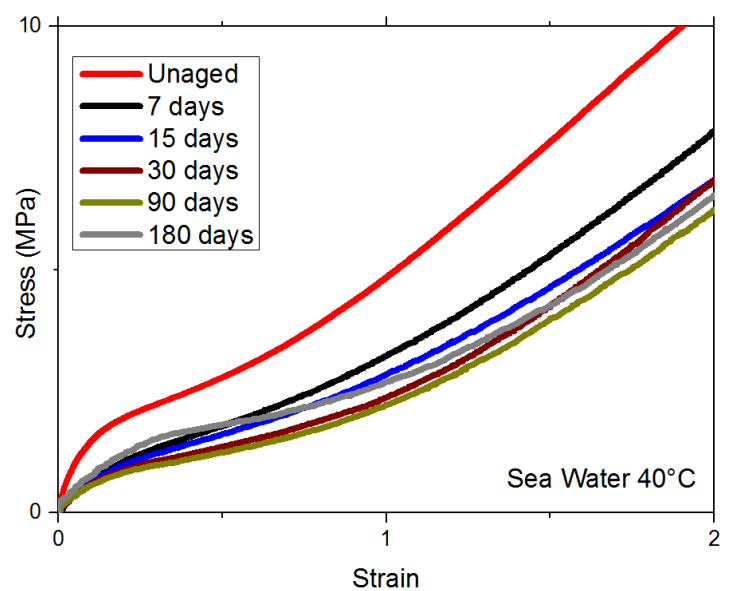

(b)

Figure 8: Tensile curves of $\mathrm{CR}$ with $45 \mathrm{phr}$ of silica as a function of immersion time in sea water at $40^{\circ} \mathrm{C}$ : (a) Stress-strain curves and (b) Zoom on the results for low strain 


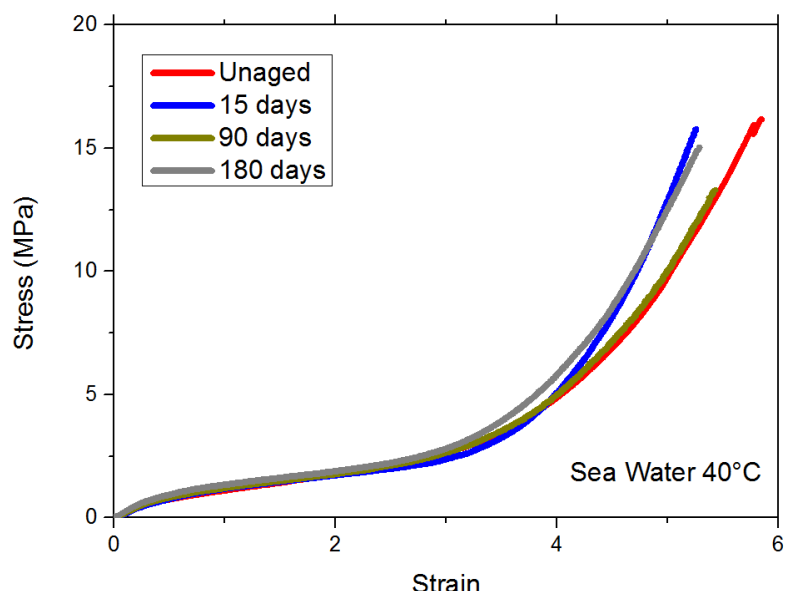

(a)

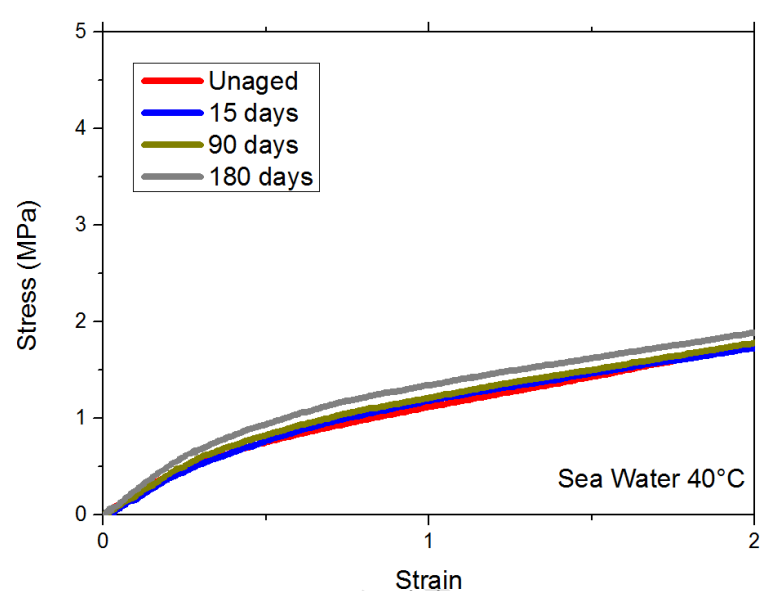

Strain

Figure 9: Tensile curves of CR with Ophr of silica as a function of immersion time in sea water at $40^{\circ} \mathrm{C}$ : (a) Stress-strain curves and (b) Zoom on the results for low strain

Based on the results presented above, it appears that polychloroprene filled with silica undergoes major changes in terms of stiffness for all temperature considered here whatever the filler content. For example, the decrease in the stress at $100 \%$ elongation reached $50 \%$ of the initial value during the ageing for the $45 \mathrm{phr}$ silica filled polychloroprene. When no silica is used, no stiffness variation occurs meaning that the filler is involved in the degradation. In addition, natural rubber with $45 \mathrm{phr}$ of silica filler was aged in sea water; the results at $40^{\circ} \mathrm{C}$ are presented in Figure 10 . Although, natural rubber and chloroprene rubber are very close in terms of chemistry, there is no change in the tensile behaviour of natural rubber filled with silica when characterized after 3 months at $40^{\circ} \mathrm{C}$ in natural seawater.

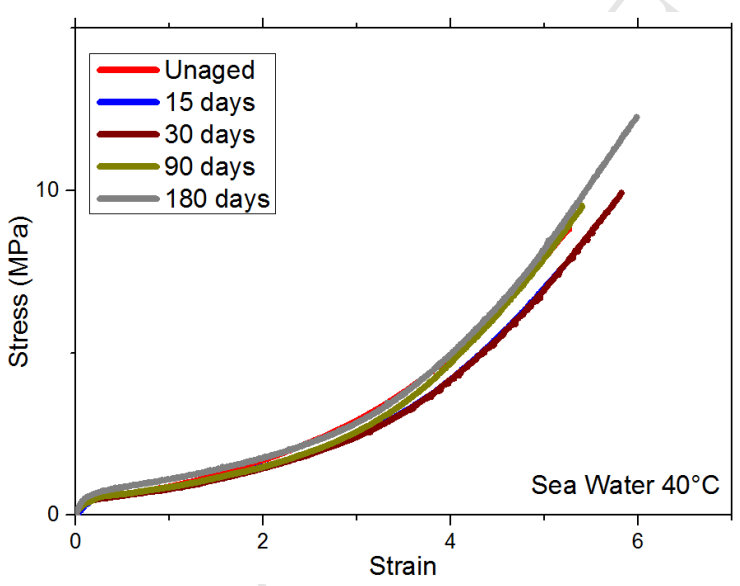

(a)

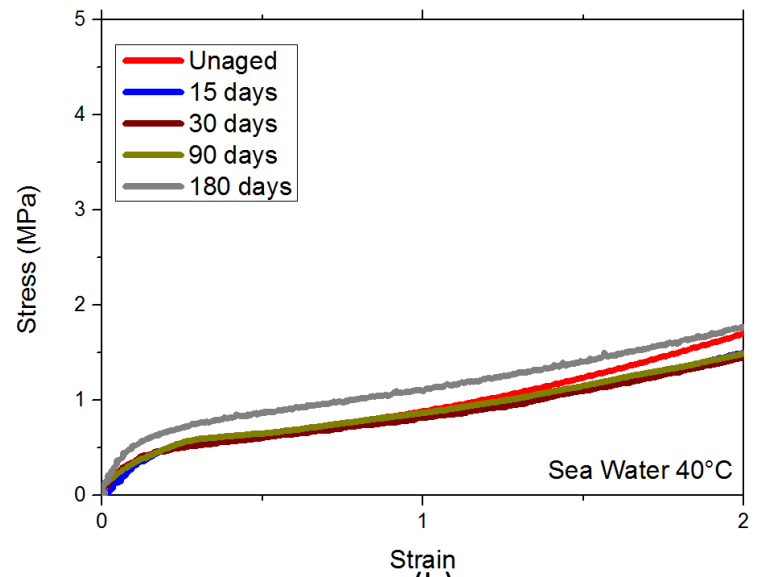

(b)

Figure 10: Tensile curves of natural rubber with $45 \mathrm{phr}$ of silica as a function of immersion time in sea water at $40^{\circ} \mathrm{C}$ : (a) Stress-strain curves and (b) Zoom on the results for low strain

In order to investigate thoroughly the degradation process of silica filled polychloroprene when used in sea water, the tensile behaviour of these rubbers was considered after ageing and drying. Using dried samples it is possible to have information about the reversible or irreversible behaviour of the degradation; this is the aim of the next section. 
Tensile tests after the drying process

When water is removed from the rubber and the sample tested in dried conditions, it appears that ageing in sea water leads to an increase in the rubber stiffness. In fact, Figure 11 shows the tensile behaviour of $\mathrm{CR}$ with $30 \mathrm{phr}$ that was aged for 6 months at $40^{\circ} \mathrm{C}$ before and after drying. This behaviour is observed for all polychloroprene rubber filled with silica as shown in Figure 12 where the variation in the stress at $100 \%$ of elongation after drying as function of ageing time is plotted.

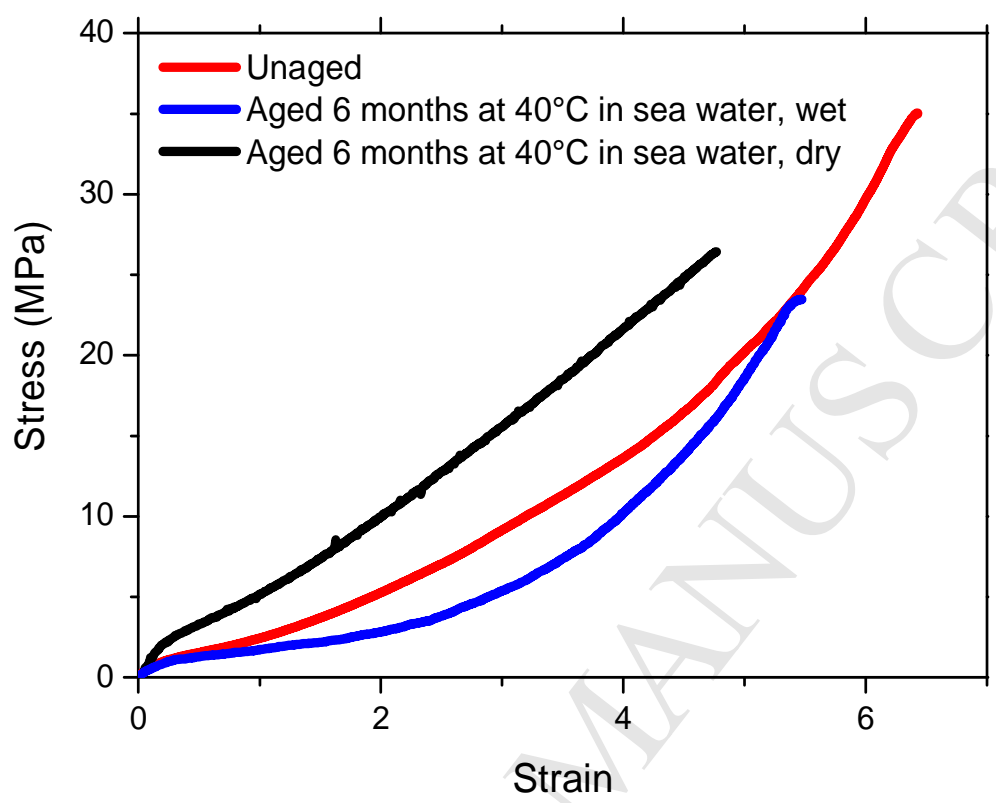

Figure 11: Effect of drying on CR filled with silica (30phr) aged 6 months at $40^{\circ} \mathrm{C}$

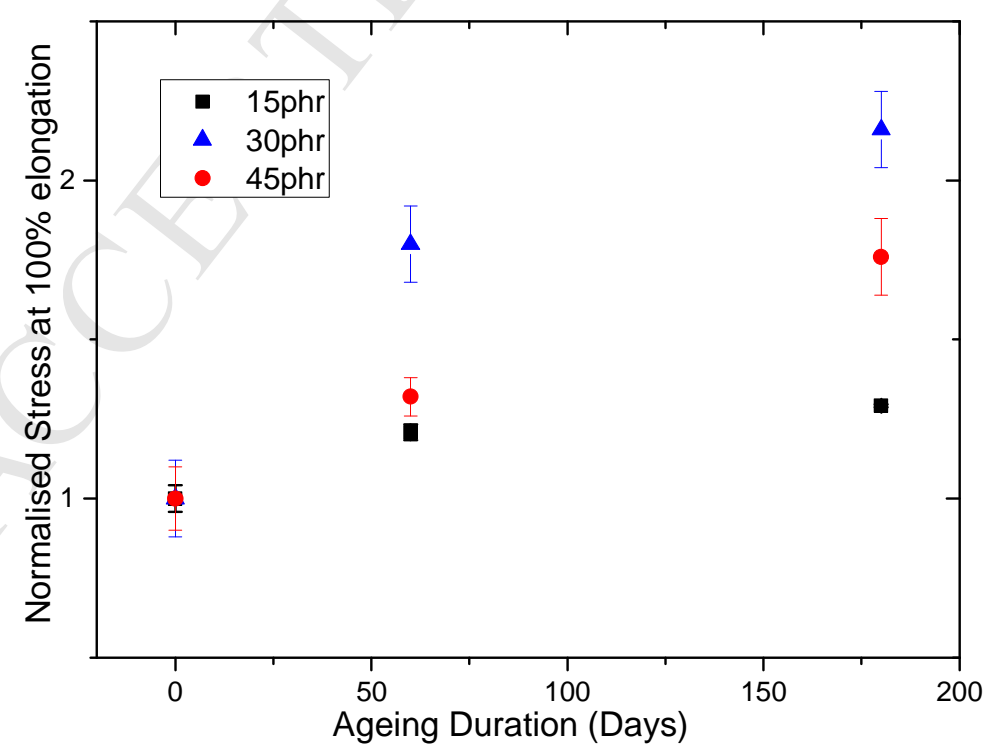

Figure 12: Increase in stress measured at $100 \%$ elongation after ageing at $40^{\circ} \mathrm{C}$ and drying 
Tensile results obtained after ageing and drying clearly show an irreversible degradation of silica filled polychloroprene rubber when used in sea water. In order to investigate the origin of the degradation, chemical characterisations were performed; results are presented in the next section.

\section{Infrared Spectroscopy}

FTIR measurements were performed on the surface of samples before and after drying in order to investigate any chemical degradation in the material during ageing. First, infrared spectra obtained with unaged samples with 30phr of silica are presented in Figure 13 and an attribution of major peaks is proposed in Table 2.

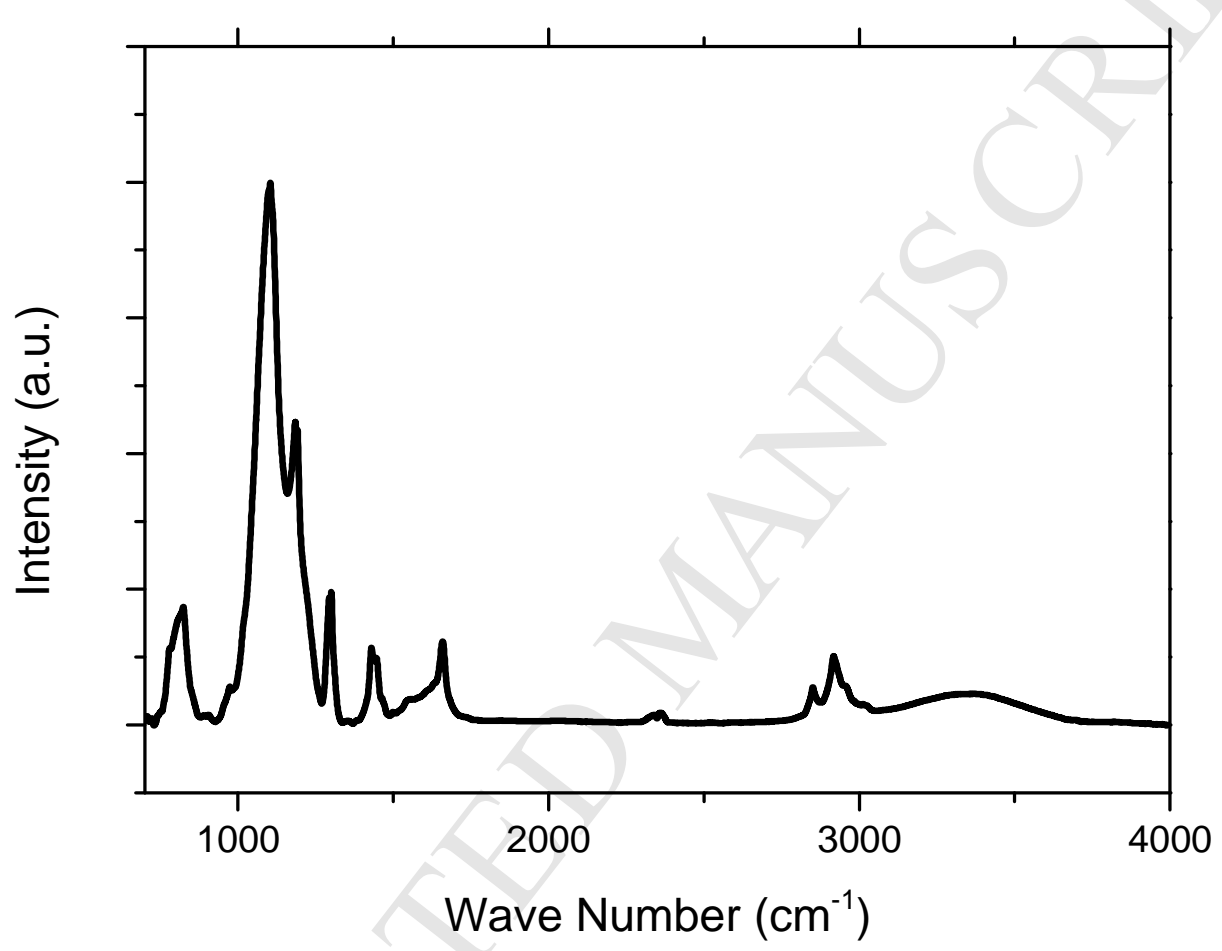

Figure 13: FTIR spectra obtained on the surface of unaged CR filled with 30phr of silica

\begin{tabular}{|c|c|}
\hline Wave Number $\left(\mathrm{cm}^{-1}\right)$ & Band assignment \\
\hline 825 & $\mathrm{C}-\mathrm{Cl}$ \\
\hline $1100 \& 1190$ & $\mathrm{Si}-\mathrm{O}$ of $\mathrm{SiO}_{2}$ \\
\hline 1450 & $\mathrm{CH} 2$ \\
\hline 1660 & $\mathrm{C}=\mathrm{C}$ \\
\hline 2850 & $\mathrm{CH} 2$ symmetric \\
\hline 2920 & $\mathrm{CH} 2$ asymmetric \\
\hline 3450 & $\mathrm{OH}$ \\
\hline
\end{tabular}

Table 2: Peak attribution in FTIR spectra of unaged polychloroprene [25]

After ageing, samples were also characterised by FTIR. For all samples filled with silica and all temperatures considered here, the same behaviour is observed: a decrease in the band related to Si$\mathrm{O}$ and a large increase in a new band situated at $1000 \mathrm{~cm}^{-1}$ and attributed to the formation of $\mathrm{SiOH}$ $[14,25]$ as shown in Figure 14. In fact, it has been shown in previous study that the band at $1000 \mathrm{~cm}^{-1}$ is a relevant indicator of silanol formation based on solid NMR results [15]. 
It is worth noting that no formation of ketone or decrease in double bound is observed here, meaning that oxidation is not involved in the degradation mechanisms [26].

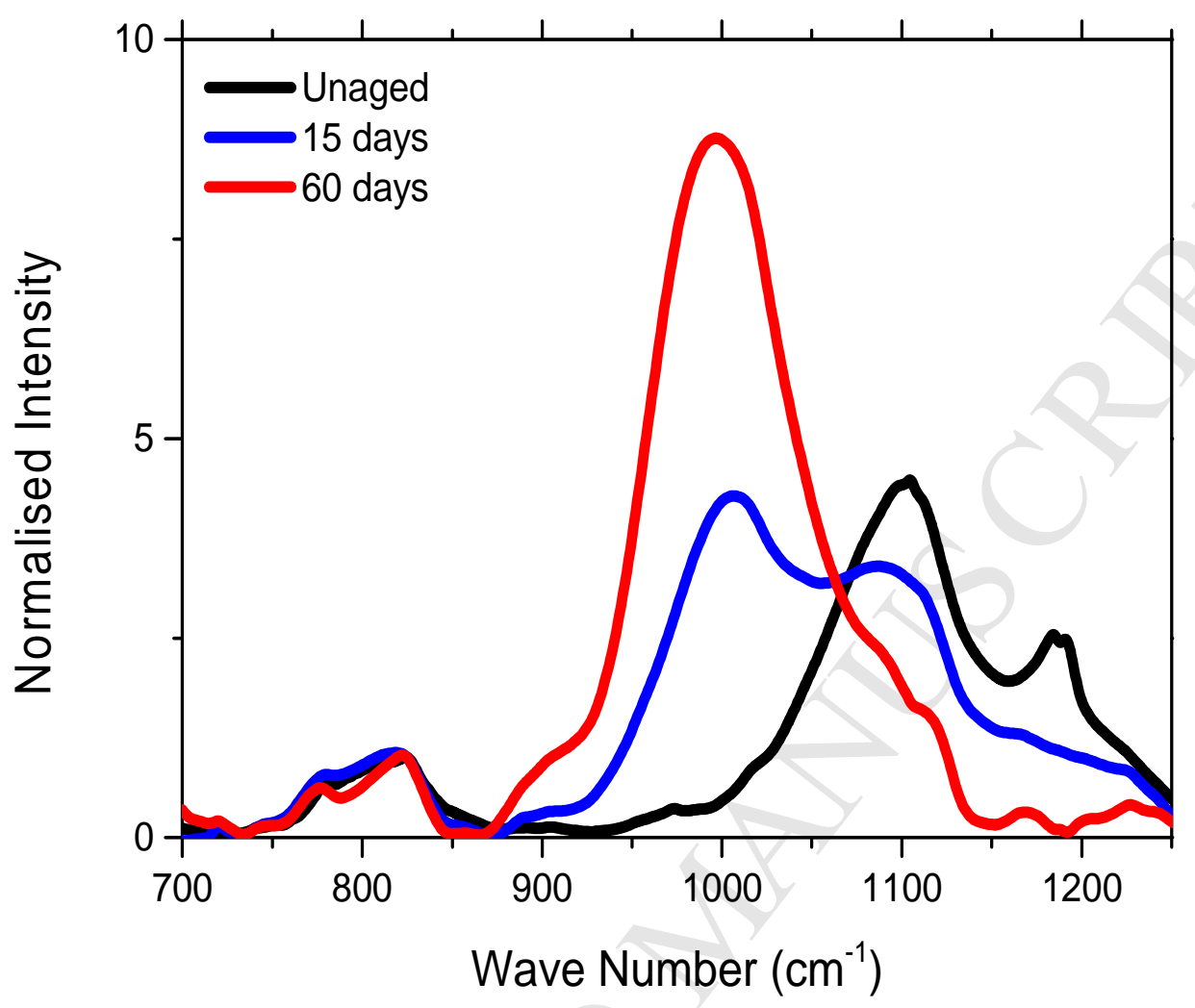

Figure 14: Formation of silanol observed by FTIR in CR filled with 30phr aged in sea water at $60^{\circ} \mathrm{C}$ SEM pictures and EDS analysis

It was hard to see the silica filler distribution in the different materials in the SEM as the elementary particle sizes are generally just a few nanometres [17]. Only some agglomerates were seen for higher filler volume fractions (30phr and 45phr) as shown in Figure 15 for the initial state and Figure 17 after ageing. EDS analysis on agglomerates observed in Figure 15 is presented in Figure 16. Results show that agglomerates are related to inorganic fillers and not to the polychloroprene matrix. 


\section{ACCEPTED MANUSCRIPT}

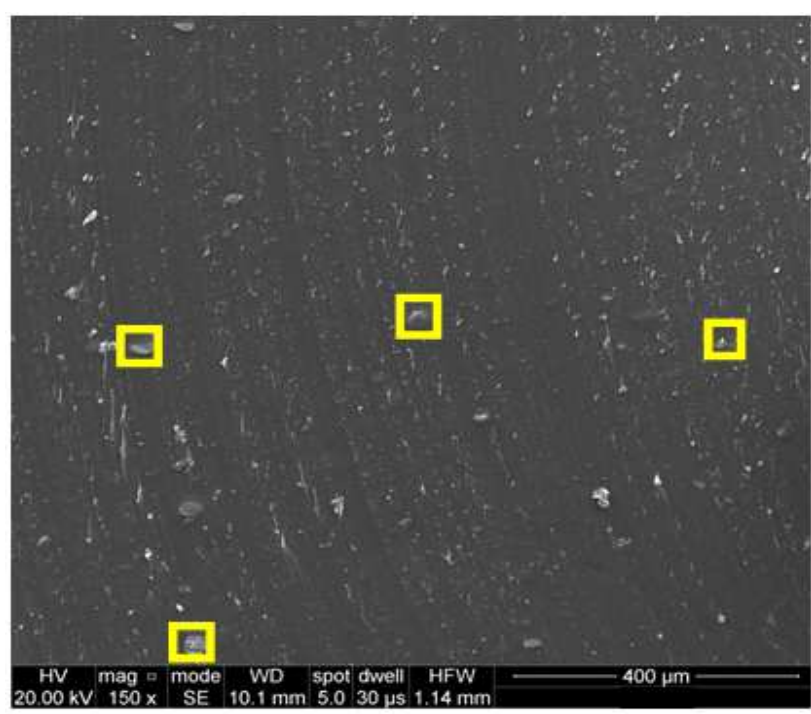

(a)

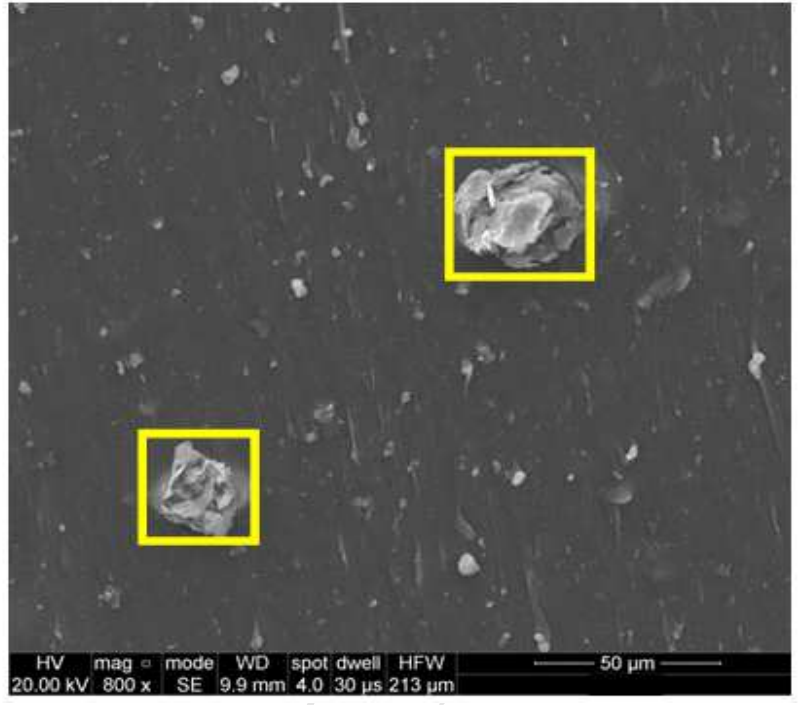

Figure 15: SEM pictures (a) Unaged CR+30phr Silica Fillers and (b) Zoom on some filler agglomerates (Yellow Square)

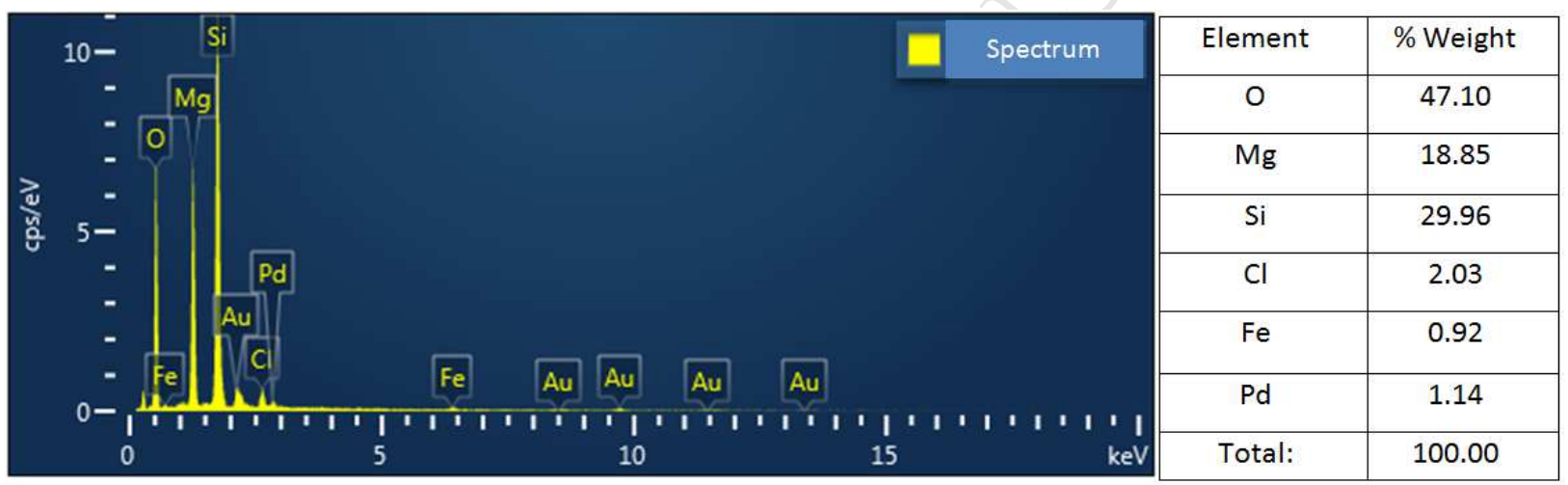

Figure 16: EDS analysis of agglomerates in unaged CR+30phr Silica Fillers
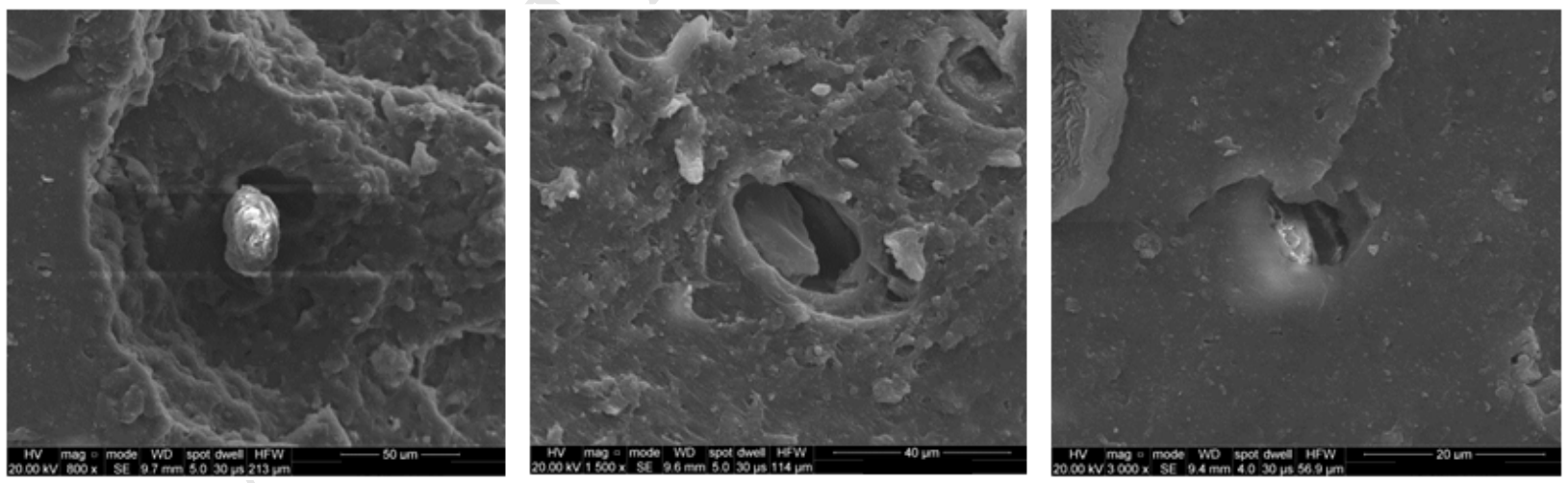

Figure 17: SEM pictures of CR+30phr Silica Fillers aged 30 days at $40^{\circ} \mathrm{C}$ in sea water: Zoom on some filler agglomerates

The main outcome of this characterisation is the fact that no large difference in either silica distribution or agglomerates is observed after ageing.

\section{Discussion}

Results obtained in this study clearly show that silica filled polychloroprene undergoes a complex degradation that leads to large changes when considering the stiffness of the rubber. This change can 
be either a decrease or an increase depending on the presence of water or not and the degree of degradation. This section aims to discuss previous results in order to understand mechanisms involved in the complex degradation.

\section{Origin of stiffness decrease induced by the presence of water}

This study clearly shows a large and rapid decrease in the stiffness of silica filled polychloroprene when immersed in sea water and tested in wet conditions. The origin of this loss is discussed below:

1 - This large decrease cannot be attributed to a modification of the polychloroprene matrix, in fact no modification of the tensile behaviour and chemistry of the unfilled CR is observed during ageing (Figure 9) meaning that the matrix remains unaffected by immersion in sea water in the conditions used in this study (i.e. a maximal temperature of $60^{\circ} \mathrm{C}$ and a maximal duration of 6 months). This is in accordance with the FTIR results obtained with unfilled CR.

2 - When silica is used as a filler in natural rubber that has a very similar chemistry to CR (presence of a double bond and same vulcanisation process) but no chlorine atom in its backbone, there are no large changes in the mechanical properties of the rubber (in the ageing conditions used here, see Figure 10). This result clearly shows two very important points; first the decrease in stiffness observed with filled CR is not related only to the filler degradation, and thus the presence of the chlorine atom plays a role in this degradation.

3-A degradation of the interaction between the silica filler and the rubber could occur during ageing in a marine environment. Let us first highlight the presence of such interactions in rubbers used here. First of all, the influence of the filler particles on the mechanical response of elastomers is most directly evaluated by considering the small strain Young's modulus. In rubber, at low deformation, it has been shown that the modulus of filled rubbers can be directly calculated based on the amount of fillers added to the rubber using Guth and Gold's equation [27]:

$$
E_{t h}=E_{0} *\left(1+2.5 * \varphi+14.1 * \varphi^{2}\right)(\mathrm{Eq} 3)
$$

Where $E_{\text {th }}$ is the theoretical modulus value for the filled rubber, $E_{o}$ the modulus of the unfilled rubber and $\varphi$ the volume fraction of fillers.

This equation has been used many times with success to link the modulus of filled and unfilled rubbers [28 - 29]. It is a combination of the Young's modulus of the matrix, the hydrodynamic effect due to the presence of filler particles and the interactions between neighbouring filler particles especially at higher volume fractions. Here, thanks to the fact that 4 polychloroprene rubbers with different amounts of silica are considered, it is possible to use this equation. A comparison between the theoretical values and experimental data is proposed in Table 3. Standard deviations are in brackets.

\begin{tabular}{|c|c|c|c|c|}
\hline Silica Content (phr) & 0 & 15 & 30 & 45 \\
\hline $\mathrm{E}_{\mathrm{th}}$ calculated using Eq 1 (MPa) & $2.3(0.2)$ & $3(0.3)$ & $3.9(0.4)$ & $4.8(0.4)$ \\
\hline $\begin{array}{c}\mathrm{E}_{\mathrm{ex}} \text { measured experimentally before } \\
\text { ageing (MPa) }\end{array}$ & $2.3(0.2)$ & $4.3(0.2)$ & $13(1)$ & $31(2)$ \\
\hline
\end{tabular}

Table 3: Comparison between theoretical and experimental values of modulus

It clearly appears that the experimental modulus are much higher than the theoretical ones especially for higher filler volume fractions. This suggests the presence of an interaction between the matrix and fillers and/or the fillers' size and dispersion effects (aggregation of particles and filler 
anisotropy). Indeed, Guth and Gold's model validity is restricted to spherical fillers and it does not take into account the interactions between the filler particles and the rubber matrix.

The interaction between the neoprene matrix and silica fillers has already been discussed in literature. In fact, according to Sae-oui [18] this interaction occurs between the chlorine atom of CR and the silanol that could be at the surface of silica fillers as represented in Figure 1 . This kind of interactions is often used to increase mechanical properties of polymers using coupling agents that contain silanol $[17,30]$.

In the presence of water, such interactions could disappear. In fact, the presence of $\mathrm{OH}$ group from water could change the hydrogen bond between $\mathrm{OH}$ from the silanol and Chlorine atom. Such modifications of interaction are very complex to characterise experimentally. However, based on the tensile results of this study, it is possible to measure the evolution of the Young's modulus of the different silica filled polychloroprene experimentally during ageing in their wet state. As proved before, all the results show a decrease in the stiffness even in non severe conditions (first times of ageing and at low temperatures). The minimal Young's modulus obtained during ageing for each material is noted in Table 4. Standard deviations are in brackets.

\begin{tabular}{|c|c|c|c|c|}
\hline Silica Content (phr) & 0 & 15 & 30 & 45 \\
\hline $\mathrm{E}_{\mathrm{th}}$ calculated using Eq 1 (MPa) & $2.3(0.2)$ & $3(0.3)$ & $3.9(0.4)$ & $4.8(0.4)$ \\
\hline $\begin{array}{c}\mathrm{E}_{\text {ex minimal }} \text { measured experimentally } \\
\text { after decrease in stiffness in } \\
\text { seawater (MPa) }\end{array}$ & $2.3(0.4)$ & $2.9(0.5)$ & $3.5(0.4)$ & $6(1)$ \\
\hline
\end{tabular}

Table 4: Comparison between theoretical and experimental values of modulus

From Table 4, it clearly appears that in presence of sea water, all the Young's moduli of silica filled CR drop to values close to theoretical values computed with Guth and Gold's model, that is to say when considering all contributions to the Young's modulus without filler-matrix interaction and agglomerate effects. It then appears that the drop in stiffness observed when silica filled polychloroprene rubbers are used in water can be attributed to the destruction of the interaction between fillers and the chlorine atom and/or the modification of the filler dispersion in sea water.

SEM pictures do not show a noteworthy change in the filler dispersion during ageing (at least filler agglomerate distribution and size) that could explain such great change in the stiffness. On the other hand, as no change was observed in the natural rubber highly filled with silica during ageing, we can say that here, sea water has no effect on the filler distribution during ageing. We can then suggest that the decrease in the stiffness during ageing in sea water is due to the modification of the interaction between the filler and the polychloroprene matrix. This phenomenon is fully reversible in the early stages of ageing in seawater when no chemical degradation occurs (no evolution in FTIR band results).

\section{Origin of stiffness increase observed after drying}

When we consider the tensile behaviour after drying, an irreversible increase in CR stiffness after ageing is clearly visible. Here again, no increase is observed after the drying of the unfilled CR or for the silica filled NR, suggesting an interaction between the filler and the chlorine atom.

In the presence of water, silica undergoes hydrolysis that leads to the formation of silanol according to the following chemical reaction [31]:

$$
\left(\mathrm{SiO}_{2}\right)_{\mathrm{x}}+2 \mathrm{H}_{2} \mathrm{O} \underset{\mathrm{k}_{2}}{\stackrel{\mathrm{k}_{1}}{\rightleftharpoons}}\left(\mathrm{SiO}_{2}\right)_{\mathrm{x}-1}+\mathrm{Si}(\mathrm{OH})_{4}
$$


The formation of silanol has been highlighted by the formation and increase in $\mathrm{Si}-\mathrm{OH}$ band and the reduction in $\mathrm{SiO}_{2}$ during ageing. Whereas this chemical reaction is balanced, it appears that during the drying process, there is no decrease in $\mathrm{Si}-\mathrm{OH}$ group because of a lower kinetic rate ( $\mathrm{k} 2)$ [29] meaning that the values measured in dried state are relevant to characterise the irreversible degradation of the polymer.

When silica undergoes hydrolysis, silanol groups are formed. In the meantime, the interaction between silica fillers and CR is related to the reactivity of silica surface area and so the concentration in silanol group [17, 32]. In that case, an increase in silanol induced by hydrolysis leads to an increase in the stiffness of polychloroprene rubber when no water is present as shown in Figure 12.

\section{I- $\quad$ Conclusion}

The role of silica fillers in polychloroprene degradation when used in sea water has been investigated using the results of an extensive experimental study considering 5 different rubbers aged for more than 6 months in natural sea water at temperatures ranging from 25 to $60^{\circ} \mathrm{C}$. Based on both the chemical and mechanical characterisations directly after ageing and after drying, it is now possible to understand the complex degradation mechanism that involves a dual process linked to an interaction between the silica filler and the polychloroprene matrix.

First of all, it clearly appears that mechanical behaviour and more especially stiffness at low deformation of silica filled CR is related to the interaction between silanol groups and chlorine atoms. The presence of water in the rubber leads to a large decrease in stiffness from the early stages of ageing whereas no chemical degradation is observed. It is now clear that this decrease is attributed to the disappearance of this interaction induced by the presence of water. This physical degradation is fully reversible when water is removed.

When considering only samples aged and then dried, an irreversible degradation is highlighted. In fact, silica fillers undergo hydrolysis, which leads to the formation of a silanol group. This silanol formation, coupled with the presence of chlorine atoms in the rubber, leads to an increase in stiffness probably due to an increase in interaction.

\section{Acknowledgements}

Special thanks to the technicians of the LCSM laboratory (IFREMER-Brest) Mickael Premel-Cabic, Nicolas Lacotte, Luc Riou and Bertrand Forest for their support during this work.

\section{$\underline{\text { References }}$}

[1] Arnaud, N., Créac'Hcadec, R., \& Cognard, J. Y. (2014). A tension/compression-torsion test suited to analyze the mechanical behaviour of adhesives under non-proportional loadings. International Journal of Adhesion and Adhesives, 53, 3-14.

[2] Le Gac, P. Y., Le Saux, V., Paris, M., \& Marco, Y. (2012). Ageing mechanism and mechanical degradation behaviour of polychloroprene rubber in a marine environment: Comparison of accelerated ageing and long term exposure. Polymer degradation and stability, 97(3), 288-296. 
[3] Maurin, R., Perrot, Y., Bourmaud, A., Davies, P., \&Baley, C. (2009). Seawater ageing of low styrene emission resins for marine composites: Mechanical behaviour and nano-indentation studies. Composites Part A: Applied Science and Manufacturing, 40(8), 1024-1032.

[4] Bowditch, M. R., \& Stannard, K. J. (1984). Effects of water absorption on the properties of a filled elastomer. Polymers in Marine Environments, 117-119.

[5] Mott, P. H., \& Roland, C. M. (2001). Aging of natural rubber in air and seawater. Rubber chemistry and technology, 74(1), 79-88.

[6] Thomas, A. G., \& Muniandy, K. (1987). Absorption and desorption of water in rubbers. Polymer, 28(3), 408-415.

[7] Graff, R. S., \&Baseden, G. A. (1999). Neoprene and Hypalon. In Rubber Technology (pp. 339-374). Springer Netherlands.

[8] Dick, J. S. (Ed.). (2014). Rubber technology: compounding and testing for performance. Carl HanserVerlag GmbH Co KG.

[9] Leveque, X. (1900, January). Behaviour of various elastomers in a marine environment. Polymers in a Marine Environment Conference.

[10] Pazur, R. J. (2014). Activation energy of poly (isobutylene) under thermo-oxidative conditions from 40 to $100^{\circ}$ C. Polymer Degradation and Stability, 104, 57-61.

[11] Colin, X., Audouin, L., Verdu, J., \& Le Huy, M. (2007). Kinetic modelling of the thermal oxidation of polyisoprene elastomers. Part 2: effect of sulfur vulcanization on mass changes and thickness distribution of oxidation products during thermal oxidation. Polymer degradation and stability, 92(5), 898-905.

[12] Celina, M. C. (2013). Review of polymer oxidation and its relationship with materials performance and lifetime prediction. Polymer Degradation and Stability, 98(12), 2419-2429.

[13] Skinner, S. J., \&Drakeley, T. J. (1933). Water Absorption by Rubber. Part II. Vulcanized Rubber. Rubber Chemistry and Technology, 6(1), 12-23.

[14] Le Saux, V., Le Gac, P. Y., Marco, Y., \& Calloch, S. (2014). Limits in the validity of Arrhenius predictions for field ageing of a silica filled polychloroprene in a marine environment. Polymer Degradation and Stability, 99, 254-261.

[15]: Le Gac, P. Y., Le Saux, V., Paris, M., \& Marco, Y. (2012). Ageing mechanism and mechanical degradation behaviour of polychloroprene rubber in a marine environment: Comparison of accelerated ageing and long term exposure. Polymer degradation and stability, 97(3), 288-296.

[16] Bueche, F. (1960). Molecular basis for the Mullins effect.Journal of Applied Polymer Science, 4(10), 107-114.

[17] Hewitt, N., \&Ciullo, P. (2007). Compounding precipitated silica in elastomers: theory and practice. William Andrew.

[18] Sae-oui, P., Sirisinha, C., Thepsuwan, U., \&Hatthapanit, K. (2007). Dependence of mechanical and aging properties of chloroprene rubber on silica and ethylene thiourea loadings. European Polymer Journal, 43(1), 185-193. 
[19] Wang, G., Li, M., \& Chen, X. (1999). Effects of fillers on mechanical properties of a waterswellable rubber. Journal of applied polymer science, 72(4), 577-584.

[20] Stockelhuber, K. W., Svistkov, A. S., Pelevin, A. G., \& Heinrich, G. (2011). Impact of filler surface modification on large scale mechanics of styrene butadiene/silica rubber composites. Macromolecules, 44(11), 4366-4381.

[21] Ismail, H., Freakley, P. K., Sutherland, I., \& Sheng, E. (1995). Effects of multifunctional additive on mechanical properties of silica filled natural rubber compound. European polymer journal, 31(11), 1109-1117.

[22] ISO. Rubber, vulcanized or thermoplastic - Determination of tensile stress-strain properties, ISO 37. 2011

[23] Celina, M., Wise, J., Ottesen, D. K., Gillen, K. T., \& Clough, R. L. (2000). Correlation of chemical and mechanical property changes during oxidative degradation of neoprene. Polymer degradation and Stability, 68(2), 171-184.

[24] Kootsookos, A., \&Mouritz, A. P. (2004). Seawater durability of glass-and carbon-polymer composites. Composites Science and Technology, 64(10), 1503-1511.

[25] Socrates, G. (2004). Infrared and Raman characteristic group frequencies: tables and charts. John Wiley\& Sons.

[26] Le Gac, P. Y., Celina, M., Roux, G., Verdu, J., Davies, P., \& Fayolle, B. (2016). Predictive ageing of elastomers: Oxidation driven modulus changes for polychloroprene. Polymer Degradation and Stability, 130, 348-355.

[27] Guth, E., \& Gold, O. (1938).On the hydrodynamical theory of the viscosity of suspensions. Phys. Rev, 53(322), 2.

[28] Wolff, S., \&Donnet, J. B. (1990). Characterization of fillers in vulcanizates according to the Einstein-Guth-Gold equation. Rubber Chemistry and Technology, 63(1), 32-45.

[29] Bergstrom, J. S., \& Boyce, M. C. (1999). Mechanical behavior of particle filled elastomers. Rubber chemistry and technology, 72(4), 633-656.

[30] Sae-oui, P., Sirisinha, C., Thepsuwan, U., \&Hatthapanit, K. (2006). Roles of silane coupling agents on properties of silica-filled polychloroprene. European polymer journal, 42(3), 479-486.

[31] Iler, R. K. (1979). The chemistry of silica: solubility, polymerization, colloid and surface pro perties, and biochemistry. Wiley.

[32] Wolff, S. (1987). Silanes in Tire Compounding After Ten Years-A Review. Tire Science and Technology, 15(4), 276-294. 